\title{
Some Considerations about Glucose Determination in Humor Vitreous to Estimate Post Mortem Interval
}

\author{
Clivia Guerrero ${ }^{1}$, Martha Fors ${ }^{2 *}$, Marjorie Rodriguez ${ }^{3}$ and Paloma Gonzalez ${ }^{4}$ \\ ${ }^{1}$ National Police of Ecuador, Profesor at Universidad de Las Américas, USA \\ ${ }^{2}$ Medical doctor, Profesor at Universidad de Las Américas, USA \\ ${ }^{3}$ Undergraduate student of Medicine, USA \\ ${ }^{4}$ Librarian at Universidad de Las Américas, USA
}

Submission: May 29, 2018; Published: June 19, 2018

*Corresponding author: Martha Fors, Medical Doctor, PhD, Professor at Universidad de Las Américas, USA, Email: martha.fors@udla.edu.ec

\begin{abstract}
The vitreous humor (HV) is a gelatinous mass similar to the egg white and occupies the vitreous cavity or posterior cavity of the ocular globe whose function is to give volume to the eye, hold the retina and maintain its transparency. The objective of this review focuses on the importance of vitreous humor in forensic biochemistry and on the importance in glucose determination in vitreous humor to estimate post mortem interval in the forensic field which is indispensable in the investigation of suspicious and violent deaths. Its location in a sterile environment for the confirmation of chemical substances, postmortem electrolytes, allows the determination of drugs, diseases such as diabetes, dehydration, malnutrition and kidney failure.
\end{abstract}

Keywords: Post mortem interval; Glucose determination; Vitreous humor

\section{Introduction}

\section{Body}

One of the aspects that stand out in the current forensic medicine is the application of auxiliary diagnostic means in the realization of the autopsies and determining the time of death and possible causes, as well as obtaining additional information to be able to reconstruct the complete sequence of the facts [1]. It is not always possible to establish patterns of cadaveric normality since many factors, exogenous and endogenous, intervene in its evolution. Many compounds undergo significant transformation processes, both qualitative and quantitative and sometimes cannot be used for the calculation of the post mortem interval (PMI), therefore only indicators that do not undergo modifications after death can be used.

The estimation of PMI by routinary methods such as early cadaveric phenomena: tissue acidification, cadaverous cooling (algor mortis), cadaveric dehydration, cadaverous lividities (livor mortis), cadaveric rigidity (rigor mortis), and late cadaveric phenomena: autolysis, putrefaction and cadaveric anthropophagy, estimate the probable time since death in hours, days, weeks, months, years or even centuries, it is important to point out that the most accurate calculation will be the earliest the autopsy is performed.
At the end of the 1960s, fluids that did not change or contaminate as quickly as blood were studied. The investigations are oriented to pericardial fluid, synovial fluid and vitreous humor (HV), due to that their autolytic changes are slowly. Postmortem blood glucose concentration is unreliable and of no diagnostic value in estimating blood glucose levels due to substantial fluctuations in glucose concentrations after death [2].

Currently, there are multiple approaches to estimating PMI that incorporate methods from almost all forensic science disciplines. One of them is to determine the concentration of glucose in vitreous humor which has advantages over other tissues because mainly its accessibility as well as other factors such its position that protects from putrefaction [3]. The chemical analysis of the fluid within the eye dates back is not new, there are evidences that it has been used for 40 years. There is little knowledge about ante-mortem vitreous concentrations, it has been suggested that significant inter-humoral differences may exist within the same individual, though one study of twentyfour individuals found this to occur significantly in only one case [4]. 


\section{Current Research in Diabetes \& Obesity Journal}

Interpretation of biochemical analyses is difficult because of post-mortem blood alterations involving glucose metabolic pathways. Vitreous humor is better preserved than blood after death, and therefore is preferentially used in thanatochemistry [5]. The thanatochemistry is an important auxiliary branch in forensic medicine although it has some limitations. In qualitative or quantitative studies of biochemical compounds, such as the glucose in the $\mathrm{HV}$, non-significant postmortem changes are evidenced, however they are important to determine previous state of hyperglycemia. Sometimes, the determination of postmortem interval, is unreliable due to substantial fluctuations in glucose concentrations after death.

There are some published scientific literature regarding the relationship between Diabetes Mellitus and the concentration of glucose in vitreous humor. In the early post-mortem period, vitreous humor has the same appearance as In vivo. With the development of body decomposition or in some ocular diseases, the vitreous humor becomes cloudy or brownish. After death, equilibrium of small molecule concentrations between blood and vitreous humor is slow, especially in case of high antemortem blood glucose concentrations [6].

Results from a study performed by Schütte [7] in the lates 70 demonstrated that there was a concentration gradient for glucose from blood via aqueous to corneal stroma and from corneal epithelium via corneal stroma to the aqueous. it was possible to increase glucose in corneal stroma by glucose or fructose infusions. Probably the sorbitol pathway plays a major role [7]. Osuna et al. [8] shown that ante-mortem serum glucose concentration was found correlated with post-mortem vitreous glucose concentrations while in another study in involving healthy and diabetic patients, vitreous glucose concentrations were found to be about half that of blood glucose concentration.

In a clinical study performed in patients with diabetic retinopathy showed that vitreous glucose concentration in non-diabetic patients was $3.5 " 1.8 \mathrm{mmol} / \mathrm{L}$ vs. 6.9 "3.6mmol/L in type 2 diabetic patients, and $9.4 " 3.3 \mathrm{mmol} / \mathrm{L}$ in type 1 diabetic patients [9]. After the cessation of cardiac and respiratory functions, surviving cells continue to metabolize blood glucose for some time and glycolysis continues spontaneously, causing a rapid decrease in blood glucose levels [2]. High vitreous glucose concentrations may be found in three main circumstances diabetic ketosis, hyperosmolar non-ketotic hyperglycemia and non-diabetic [10] Some authors have reported fatal high glucose concentrations in vitreous humor (range from $7.0 \mathrm{mmol} / \mathrm{L}$ to more than $13 \mathrm{mmol} / \mathrm{L})[10,11]$.

Karlovsek [11] also compared glycated hemoglobin, glucose, lactate, and combined glucose and lactate concentrations in vitreous and cerebrospinal fluid in a group of diabetics and healthy subjects. This author proposed that vitreous glucose concentrations over $13 \mathrm{mmol} / \mathrm{L}$ or $234 \mathrm{mg} / \mathrm{dL}$ could indicate antemortem hyperglycemia suggesting that increased vitreous glucose levels were diagnostic of antemortem blood hyperglycemia.

In the study performed by Vivero et al. [12] significant differences were found for the combined concentrations of glucose and fructosamine between the diagnostic groups. In fact, they were five times higher in the group of diabetic subjects than in the control group. At autopsy, the sum of the levels of glucose and lactic acid in the vitreous of subjects with hypoglycemia and hyperglycemia, may be indicative of glucose levels at the time of death. Lactate and glucose sums more than $450 \mathrm{mg} / \mathrm{dL}$ in the vitreous, contribute to deaths related to acute hyperglycemia, whereas sums less than $50 \mathrm{mg} / \mathrm{dL}$ are a clear sign of fatal situations of hypoglycemia [13].

The disadvantages of the HV analysis are that the analytical methods are currently calibrated and validated for the analysis of plasma and urine. Another problem is the high viscosity of the vitreous humor, which hinders the repetitiveness in the analysis of the same electrolyte, in the same sample and by the same analyst, it has been tried to reduce such viscosity by different pre-treatment methods of the sample. The recommendation is the use of hyaluronidase, heating, ultrasound liquefaction and centrifugation, either separately or in combination. Heat and treatment with hyaluronidase generate slightly higher and lower values in the measurement of electrolytes and glucose.

According Milton Helpern, Eduardo Vargas Alvarado remembered his criterion of "The estimate of the postmortem interval is one of the most difficult and imprecise techniques in the forensic pathology, none of the tests is accurate and all the possible evidence must be correlated to try arrive at some sensible chronological criterion within which there could be [14].

\section{Conclusion}

The vitreous humor occupies almost $80 \%$ of the eyeball, is located in the free space between the lens and the retina, contains cells such as hyalocytes and fibroblasts that give the viscoelectric properties, chemically composed of sodium, potassium, calcium, magnesium, chlorine, lactate, glucose, among others. Its postmortem utility is in the determination of glucose, urea nitrogen, uric acid, creatinine, sodium, chlorine, and can be used to document diabetes, hydration levels, electrolyte balance and renal function status antemortem.

The collection and handling of the sample is relatively simple, due to the location within the eye, and its physical and chemical conditions are highly stable, and the level of contamination is lower than the rest of tissues. Severe hyperglycemic states causing death can be diagnosed by vitreous glucose assay. Vitreous glucose may be a useful marker of antemortem glycemic state in combination with glycated hemoglobin dosage in blood and could be use in the estimates of postmortem interval. 


\section{Current Research in Diabetes \& Obesity Journal}

\section{References}

1. Gisbert Calabuig JA, Verdú Pascual FA (1998) Autopsia médico-legal. In: Gisbert Calabuig JA (Ed.), Medicina Legal y Toxicología. Masson, Barcelona.

2. Palmiere C (2015) Postmortem diagnosis of diabetes mellitus and its complications. Croat Med J 56(3): 181-193.

3. Madea B (2005) Is there recent progress in the estimation of the postmortem interval by means of thanatochemistry? Forensic Sci Int 151(2-3): 139-149.

4. Tagliaro F, Bortolotti F, Manetto G, Cittadini F, Pascali VL, et al. (2001) Potassium concentration differences in the vitreous humour from the two eyes revisited by microanalysis with capillary electrophoresis. J Chromatogr A 924(1-2): 493-498.

5. Boulagnon C, Garnotel R, Fornes P, Gillery P (2011) Post-mortem biochemistry of vitreous humor and glucose metabolism: an update. Clin Chem Lab Med 49(8): 1265-1270.

6. Zilg B, Alkass K, Berg S, Druid H (2009) Post-mortem identification of hyperglycemia. Forensic Sci Int 185(1-3): 89-95.

7. Schütte E (1977) Nutrition metabolites in the anterior eye segments. Studies on model experiments and on man. Fortschr Med 95(23) $1533-1534$

his work is licensed under Creative Commons Attribution 4.0 Licens

OI: $10.19080 / C R D 0 J .2018 .07 .555718$
8. Osuna E, Garcia Vıllora A, Perez Carceles MD, Conejero J, Abenza JM, et al. (1999) Vitreous humor fructosamine concentrations in the autopsy diagnosis of diabetes mellitus. Int J Legal Med 112(5): 275-279.

9. Lundquist O, O"sterlin S (1994) Glucose concentration in the vitreous of non-diabetic and diabetic human eyes. Graefes Arch Clin Exp Ophthalmol 232(2): 71-74.

10. Chaturvedi AK, Botch SR, Canfield DV, Forster EM (2009) Vitreous fluid and/or urine glucose concentrations in 1335 civil aviation accident pilot fatalities. J Forensic Sci 54(3): 715-720.

11. Karlovsek MZ (2004) Diagnostic values of combined glucose and lactate values in cerebrospinal fluid and vitreous humour: our experiences. Forensic Sci Int 146(Suppl): S19-S23.

12. Vivero G, Vivero Salmerón G, Pérez Cárceles MD, Bedate A, Luna A, et al. (2008) Combined determination of glucose and fructosamine in vitreous humor as a post-mortem tool to identify antemortem hyperglycemia. Rev Diabet Stud 5(4): 220-224.

13. Oehmichen M, Auer R, König H (2009) Forensic neuropathology and associated neurology. Berlin, Germany.

14. Alvarado EV (2015) Tanatología forense. Trillas, México.

\section{Your next submission with Juniper Publishers will reach you the below assets}

- Quality Editorial service

- Swift Peer Review

- Reprints availability

- E-prints Service

- Manuscript Podcast for convenient understanding

- Global attainment for your research

- Manuscript accessibility in different formats

(Pdf, E-pub, Full Text, Audio)

- Unceasing customer service

Track the below URL for one-step submission https://juniperpublishers.com/online-submission.php 